\title{
$\beta$-Hydroxybutyrate Facilitates Fatty Acids Synthesis Mediated by Sterol Regulatory Element-Binding Protein1 in Bovine Mammary Epithelial Cells
}

\author{
Min Zhang ${ }^{a}$ Shiqi Zhanga Qi Huib ${ }^{\text {Lin Lei }}{ }^{a}$ Xiliang Du ${ }^{a}$ Wenwen Gao \\ Renhe Zhang ${ }^{\mathrm{a}}$ Guowen Liu ${ }^{\mathrm{a}}$ Xiaobing Lia Xinwei Lia \\ aCollege of Veterinary Medicine, Jilin University, Changchun, 'bSchool of Pharmacy, Wenzhou Medical \\ University, Chashan University Park, Wenzhou, China
}

\section{Key Words}

BHBA • SREBP1 1 Fatty acids synthesis $•$ Bovine mammary epithelial cells

\begin{abstract}
Background/Aims: In dairy cows, $\beta$-hydroxybutyrate (BHBA) is utilized as precursors of de novo synthesized fatty acids in mammary gland. Ketotic cows are characterized by excessive negative energy balance (NEB), which can further increase the blood BHBA concentration. Sterol regulatory element-binding protein1 (SREBP1) and cell death-inducing DNA fragmentation factor-alpha-like effector $\alpha$ (Cidea) play crucial roles in lipid synthesis. Therefore, we hypothesized that BHBA could stimulate SREBP1/Cidea pathway to increase milk fat synthesis in bovine mammary epithelial cells. Methods: Bovine mammary epithelial cells were treated with different concentrations of BHBA and transfected with adenovirus to silence SREBP1 expression. The effects of BHBA on the lipid synthesis in bovine mammary epithelial cells were investigated. Results: The results showed that BHBA could significantly increase the expression of SREBP1, fatty acid synthase (FAS), acetyl-CoA carboxylase $\alpha$ (ACC- $\alpha$ ), Cidea and diacylglycerol transferase-1 (DGAT-1), as well as the triglycerides (TG) content in bovine mammary epithelial cells. BHBA treatment also increased the transfer of mature SREBP1 to nucleus compared with control group. However, SREBP1 silencing could significantly downregulate the overexpression of FAS, ACC- $\alpha$, Cidea and DGAT-1, as well as TG content induced by BHBA. Conclusion: The present data indicate that BHBA can significantly increase TG secretion mediated by SREBP1 in bovine mammary epithelial cells.
\end{abstract}

Copyright $\odot 2015$ S. Karger AG, Basel

\section{Introduction}

The mechanism of carbohydrate digestion and nutrient metabolism in ruminants differs significantly from that in monogastric animals. Cellulose and starch are the main

M. Zhang, S. Zhang and Q. Hui contributed equally to this study.

Guowen Liu, Xiaobing Li and Xinwei Li

College of Veterinary Medicine, Jilin University, 5333 Xi'an Road, Changchun, 130062 Jilin, (China)

E-Mail liuguowen2008@163.com, E-Mail xbli@jlu.edu.cn, E-Mail lixinwei100@126.com 


\section{Cellular Physiology Cell Physiol Biochem 2015;37:2115-2124 \\ \begin{tabular}{ll|l} 
and Biochemistry & $\begin{array}{l}\text { DOI: } 10.1159 / 000438569 \\
\text { Published online: November 25, } 2015\end{array}$ & $\begin{array}{l}\text { C) 2015 S. Karger AG, Basel } \\
\text { www.karger.com/cpb }\end{array}$ \\
\hline Zhang et al: $\beta$-Hydroxybutyrate Facilitates Fatty Acids Synthesis Mediated by SREBP1
\end{tabular}}

carbohydrates for ruminants. Ruminal micro-organisms convert cellulose and starch to volatile fatty acids (VFAs, including acetic acid, propionic acid, and butyric acid), carbon dioxide, and methane [1]. Butyric acid is absorbed and metabolized into $\beta$-hydroxybutyrate (BHBA) by ruminal epithelium cells. BHBA is the main precursor of milk fat synthesis in ruminants [2]. Importantly, perinatal dairy cows usually experience a period of negative energy balance (NEB) induced by decreased dry matter intake and increased energy demand. Excessive NEB leads to lipid mobilization then results in high blood concentrations of non-esterified fatty acids (NEFAs) [3]. Ketone bodies are generated when large amount of NEFAs are beyond the oxidative ability of liver [4]. BHBA is one of the primary ketone bodies, a golden biochemical indicator for ketosis detection [5]. The plasma concentrations of BHBA in normal dairy cows are less than $1.2 \mathrm{mM}$; however, if subclinical or clinical ketosis develops, BHBA levels will exceed $1.2 \mathrm{mM}$ or $1.5 \mathrm{mM}$, respectively [6, 7].

Several studies have indicated that BHBA played different roles in specific tissue and species. Recent research suggested that BHBA functioned as a signal molecule activating some signal pathways involved in inflammation and thermogenesis $[8,9]$. In ruminants, BHBA is utilized as precursors of de novo synthesized fatty acids in bovine mammary gland [10]. During the first and second week post-calving, elevated serum BHBA results in greater milk fat percentage and less milk protein percentage [11]. These studies indicated that BHBA could influence milk fat synthesis in mammary epithelial cells of dairy cow.

Sterol regulatory element-binding protein 1 (SREBP1), a member of transcription factors consists of SREBP-1a and SREBP-1c, belongs to the basic helix-loop-helix-leucinezipper (bHLH-Zip) family $[12,13]$. Although SREBP-1a and SREBP-1c are encoded by one gene (SREBP1), they are different in sequence at both their 5' and 3' ends $[12,13]$. SREBP-1a regulates the genes required in the synthesis of cholesterol and fatty acid, while SREBP1c preferentially regulates genes involved in synthesis and uptake of fatty acids and TG synthesis $[12,14,15]$. The membrane-bound SREBP1 molecule is synthesized as a $125 \mathrm{kDa}$ precursor before cleaved to a 68kDa mature form which translocates to the nucleus [13]. Studies demonstrated that Liver X receptor (LXR) activation upregulated the expression of SREBP1 and promoted de novo fatty acids synthesis in bovine mammary epithelial cells [16]. Overexpression of SREBP1 significantly increased milk fat synthesis; otherwise, fatty acids synthesis as well as TG secretion were decreased due to SREBP1 gene silencing in dairy cow mammary epithelial cells (DCMECs) [12]. Therefore, these studies demonstrated that SREBP1 played a crucial role in fatty acids synthesis in bovine mammary epithelial cells.

Cell death-inducing DNA fragmentation factor-alpha-like effector $\alpha$ (Cidea) is related to the development of metabolic disorders, including hepatic steatosis, insulin sensitivity and obesity [17]. Wang et al. reported that SREBP-1c directly mediated the effect of insulin on Cidea in hepatocytes [18]. Numerous studies indicated that Cidea mediated small lipid droplets (LD) become large LD and promoted TG accumulation [19, 20]. In addition, Cidea is highly expressed in the mammary glands of lactation period and partially acts as a transcriptional co-activator regulating secretion of milk lipids in mouse [21]. However, the role of Cidea on milk fat synthesis in bovine mammary epithelial cells of dairy cows is not well defined.

High producing dairy cows are more susceptible to subclinical ketosis, resulting in a high milk fat and lower milk production $[11,22]$. The increased milk fat may be associated with the elevated concentrations of BHBA. This arouses our interesting to explore the underlying mechanism. Therefore, the aim of this study is to investigate whether BHBA facilitates milk fat synthesis mediated by SREBP1/Cidea in bovine mammary epithelial cells cultured in vitro.

Materials and Methods

Cell culture

Experiments were performed using a primary culture of bovine mammary epithelial cells purchased from Jennio Biotech company (Guangzhou, China) and cultured in $25 \mathrm{~cm}^{2}$ cell culture flasks. Cells were 


\section{Cellular Physiology Cell Physiol Biochem 2015;37:2115-2124 \begin{tabular}{ll|l} 
DOI: 10.1159/000438569 & $\begin{array}{l}\text { O 2015 S. Karger AG, Basel } \\
\text { www.karger.com/cpb }\end{array}$ \\
\hline
\end{tabular}}

cultured in DMEM/F12 medium supplemented with 10\% fetal bovine serum (FBS), $100 \mathrm{U} / \mathrm{mL}$ penicillin, and $100 \mathrm{ug} / \mathrm{mL}$ streptomycin at $37^{\circ} \mathrm{C}$ with $5 \% \mathrm{CO}_{2}$. Cells were detached with $0.05 \%$ trypsin, $0.53 \mathrm{mM}$ EDTA and incubated at $37^{\circ} \mathrm{C}$ for 3 minute and were passage into other three new cell culture flasks when the cell density reached $80 \%$. Then, the cells were resuspended in culture medium and seeded in 6-well plates at a density of $1 \times 10^{4}$ cells $/ \mathrm{cm}^{2}$ ( $2 \mathrm{~mL}$ per well). Before treatments, cells were passaged three times. Medium was changed once $24 \mathrm{~h}$.

\section{BHBA treatment and transfection}

The concentrations of BHBA used in this study were chosen according to the serum BHBA concentration in cows with ketosis [23]. Before treatments, the cells were serum-starved for $12 \mathrm{~h}$. Bovine mammary epithelial cells were treated with $0,0.6,1.2,2.4 \mathrm{mM}$ BHBA for $24 \mathrm{~h}$ and cultured in serum-free medium at $37^{\circ} \mathrm{C}$ with $5 \% \mathrm{CO}_{2}$. For infection experiment, an adenovirus to silence SREBP1 (AD-GFP-shSREBP1) was delivered to the cells; after $24 \mathrm{~h}$, cells were treated with $1.2 \mathrm{mM}$ BHBA for another $24 \mathrm{~h}$. Control group was infected with empty adenovirus vector (AD-GFP). Then, cells were harvested for analysis. The shRNA sequence was 5'GCT CTT CTC CTT GGC ACT TCT3'. Construction of SREBP1 recombinant adenovirus was completed by SinoGenoMax company (Beijing, China). The titer of virus reached to $10^{10} \mathrm{PUF} / \mathrm{mL}$.

\section{Total RNA isolation and Real-time PCR}

The total RNA was extracted by TRIzol reagent (TaKaRa Biotechnology Co., Ltd., Tokyo, Japan) following the manufacturer's instructions. The RNA was reverse-transcribed to cDNA using PrimeScript Reverse Transcriptase (TaKaRa Biotechnology Co., Ltd., Tokyo, Japan) according to the manufacturer's protocol. The relative mRNA concentrations were detected by qRT-PCR using a 7500 Real-Time PCR System (Applied Biosystems, USA) and a SYBR green plus reagent kit (Roche, Norwalk, CT, USA). The conditions were as follows: $95^{\circ} \mathrm{C}$ for $3 \mathrm{~min}$, followed by 40 cycles of $95^{\circ} \mathrm{C}$ for $15 \mathrm{sec}$ and $60^{\circ} \mathrm{C}$ for $1 \mathrm{~min}$. Gene-specific primers used for qRT-PCR were listed in Table 1. Standard curves of the primers and the amplification efficiency were calculated as previously described [24]. The efficiency of used primers was shown in Table 2. The relative expression levels were normalized to $\beta$-actin levels. Fold change was calculated using $2^{-\Delta \Delta \mathrm{Ct}} \operatorname{method}$ with the control group as the calibrator as previously described [25].

\section{Western blot analysis and antibodies}

The cells were collected and washed twice with cold phosphate-buffered saline (PBS). Total cellular proteins were extracted using a protein extraction kit (Sangon Biotech Co., Ltd., Shanghai, China). Protein

Table 1. The primers sequences used for cDNA generation

\begin{tabular}{lllc}
\hline Gene & Sequence number & Primer sequences(5'-3') & Length(bp) \\
\hline SREBP1 & NM_001113302.1 & $\begin{array}{l}\text { For CGACACCACCAGCATCAACCACG } \\
\text { Rev GCAGCCCATTCATCAGCCAGACC }\end{array}$ & 109 \\
FAS & NM_001012669.1 & $\begin{array}{l}\text { For ACAGCCTCTTCCTGTTTGACG } \\
\text { Rev CTCTGCACGATCAGCTCGAC }\end{array}$ & 144 \\
ACC- $\alpha$ & NM_174224.2 & $\begin{array}{l}\text { For TCCTGCTGCTATTGCTACTCCA } \\
\text { Rev CAGTCCCCGCACTCACATAA }\end{array}$ & 95 \\
Cidea & NM_001083449.1 & $\begin{array}{l}\text { For TCAGGCCCCTGACGTTTATG } \\
\text { Rev CACCAGTGCATCCAAGGTCT }\end{array}$ & 167 \\
DGAT-1 & NM_174693.2 & $\begin{array}{l}\text { For GGCAGAACTGGAACATCCCT } \\
\text { Rev TGCCCGATGATGAGTGACAG }\end{array}$ & 274 \\
$\beta$-actin & BC142413.1 & $\begin{array}{l}\text { For GCCCTGAGGCTCTCTTCCA } \\
\text { Rev GCGGATGTCGACGTCACA }\end{array}$ & 101 \\
\hline
\end{tabular}

Table 2. Regression coefficients $\left(R^{2}\right)$, amplification efficiency [ $\left.E=\left(10^{-1 / \text { slope }}-1\right) \times 100 \%\right]$ and slope of the standard curves of the primer sets

\begin{tabular}{lcccccc}
\hline Gene & SREBP1 & FAS & ACC- $\alpha$ & Cidea & DGAT-1 & $\beta$-actin \\
\hline $\mathrm{R}^{2}$ & 0.9969 & 0.9985 & 0.9835 & 0.9997 & 0.9888 & 0.9902 \\
Slope & -3.3408 & -3.1223 & -3.2847 & -3.5924 & -3.4634 & -3.1069 \\
$\mathrm{E}$ & $99 \%$ & $109 \%$ & $102 \%$ & $90 \%$ & $95 \%$ & $109 \%$ \\
\hline
\end{tabular}




\section{Cellular Physiology Cell Physiol Biochem 2015;37:2115-2124

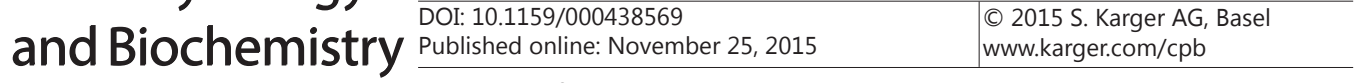 \\ Zhang et al.: $\beta$-Hydroxybutyrate Facilitates Fatty Acids Synthesis Mediated by SREBP1}

concentrations were determined using the BCA Protein Assay Kit (Beyotime, china). Proteins were separated by SDS-PAGE (12\% gel for SREBP1 and Cidea; $8 \%$ gel for ACC- $\alpha$ and FAS) with known molecular weight makers (Sangon Biotech Co., Ltd., Shanghai, China). SDS-PAGE separation was performed with 40 ug of proteins per lane. The proteins were subsequently transferred onto $0.45 \mu \mathrm{m}$ PVDF membranes. Then, the membranes were blocked with Tris-HCL $(0.05 \mathrm{M}$ Tris, pH7.4, $0.2 \mathrm{M} \mathrm{NaCl})$ buffer solution containing $0.1 \%$ Tween-20 (TBS-T), supplemented with 3\% BSA at room temperature for $4 \mathrm{~h}$. The membranes were incubated with antibodies at $4^{\circ} \mathrm{C}$ overnight. Next, the membranes were washed with TBS-T for three times, followed by incubation with secondary antibody conjugated peroxidase for $45 \mathrm{~min}$ at room temperature. Then, the membranes were washed four times for $5 \mathrm{~min}$ and an immunodetection analysis was performed using an enhanced chemiluminescence solution (ECL, Pierce Biotechnology Inc., Chicago, IL, USA). Antibodies against Cidea (Abcam, Cambridge, UK) diluted at 1:500 in TBS-T, SREBP1 (Novus, USA) diluted at 1:1000 in TBS-T, FAS (CST, Danvers, USA) diluted at 1:500 in TBS-T, ACC (Abcam, Cambridge, UK) diluted at 1:1000 in TBS-T, $\beta$-actin (Santa Cruz, USA) diluted at 1:1000 in TBS-T. HRP-conjugated goat, anti-mouse or anti-rabbit secondary antibody (Boster, Wuhan, China) diluted at 1:5000 in TBS-T. Protein grey intensity was quantified by the Gel-Pro Analyzer program normalized to $\beta$-actin levels.

\section{ELISA assay}

After the bovine mammary epithelial cells were treated with BHBA and adenovirus, the medium from the 6-well plates was collected. The TG content secreted by bovine mammary epithelial cells were determined using a bovine enzyme-linked immunosorbent assay (ELISA) kit (Sunred Technology Co., Ltd., Shanghai, China) following the manufacturer's instructions.

\section{Immunocytofluorescence}

The cells were grown on glass coverslips to $70 \%$ confluency and subjected to BHBA or adenovirus treatments as described above. Upon completion of the treatment, the coverslips were washed with PBS, fixed with 4\% w/v paraformaldehyde in PBS for $20 \mathrm{~min}$ at room temperature, subjected to antigen retrieval with EDTA $2 \mathrm{Na}\left(95^{\circ} \mathrm{C}, 5 \mathrm{~min}\right)$ and permeabilized with $0.1 \%$ Triton X-100 (Sigma-Aldrich, St. Louis, MO). After further washing, the cells were exposed to the primary antibody SREBP1 (Novus, USA) at 1:100 in PBS at $4^{\circ} \mathrm{C}$ overnight and then incubated with goat anti-rabbit IgG conjugated with cy3 (Beyotime, China) at 1:200 in PBS at room temperature for 30 min and counterstained with Hoechst 33258 (Beyotime, China). The coverslips were observed and photographed using laser-scanning confocal microscopy (Fluoview FV1200, Olympus, Japan).

\section{Statistical analysis}

The results are presented as the mean \pm SEM and were analyzed using Statistical Package for the Social Sciences (SPSS) 13.0 software (SPSS Incorporated, Chicago, IL, USA). Nine replicate samples were used for each condition. ANOVA was performed to evaluate the differences among the groups followed by LSD post hoc test. A p value lower than 0.05 was considered statistically significant (labeled with one star), and a $\mathrm{p}$ value lower than 0.01 was considered highly significant (labeled with two stars).

\section{Results}

BHBA promotes de novo fatty acids synthesis

To determine whether BHBA can affect fatty acids synthesis, mammary epithelial cells were treated with different concentrations of BHBA. The mRNA and protein expression of SREBP1 and its target molecules Cidea, fatty acid synthase (FAS), acetyl-CoA carboxylase $\alpha$ (ACC- $\alpha$ ) and diacylglycerol transferase-1 (DGAT-1) involved in TG synthesis were detected using qRT-PCR and Western-blotting, respectively. The results showed that the mRNA levels of SREBP1, FAS, ACC- $\alpha$, Cidea and DGAT- 1 were significantly increased in BHBA-treated groups with the highest levels in the $1.2 \mathrm{mM}$ BHBA-treated group (Fig. 1A-E). What's more, the protein levels of SREBP1, FAS, ACC- $\alpha$ and Cidea were also significantly increased (Fig. 2AE). These results indicate that BHBA can increase the expression of lipogenic transcription factor SREBP1 and lipid synthesis enzymes Cidea, FAS, ACC- $\alpha$ and DGAT-1. 


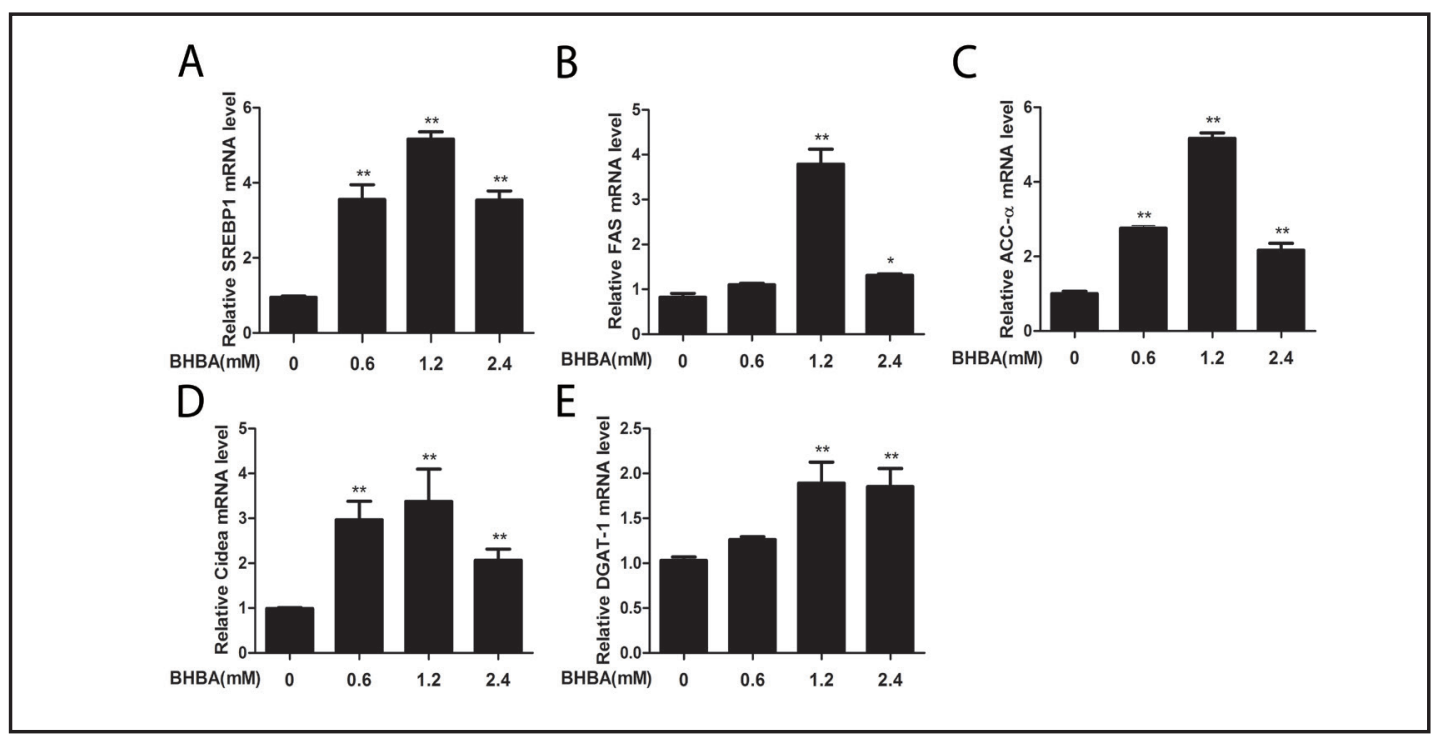

Fig. 1. Effects of different concentrations of BHBA on SREBP1, FAS, ACC- $\alpha$, Cidea and DGAT-1 mRNA expression in bovine mammary epithelial cells. Cells were treated with 0, 0.6, 1.2, $2.4 \mathrm{mM}$ BHBA for $24 \mathrm{~h}$. Nine replicate samples were used for each condition. (A) The mRNA level of SREBP1. (B) The mRNA level of FAS. (C) The mRNA level of ACC- $\alpha$. (D) The mRNA level of Cidea. (E) The mRNA level of DGAT-1. The data are shown as the mean \pm SEM. *, statistical significance $(\mathrm{P}<0.05) .{ }^{* *}$, statistical significance $(\mathrm{P}<0.01)$. The symbol $^{*}$ and $* *$ indicate statistical differences with the control group (no BHBA).

Fig. 2. BHBA promotes de novo fatty acids synthesis. Cells were treated as described in Fig. 1. (A) Western blots of $\beta$-actin, SREBP1, FAS, ACC- $\alpha$ and Cidea. (B) Relative protein expression level of SREBP1 normalized to $\beta$-actin. (C) Relative protein expression level of Cidea normalized to $\beta$-actin. (D) Relative protein expression level of FAS normalized to $\beta$-actin. (E) Relative protein expression level of ACC- $\alpha$ normalized to $\beta$-actin. The data are shown as the mean \pm SEM. $*$, statistical significance $(P<0.05) .{ }^{* *}$, statistical significance $(P<0.01)$. The symbol $^{*}$ and ${ }^{* *}$ indicate statistical differences with the control group (no BHBA).
A

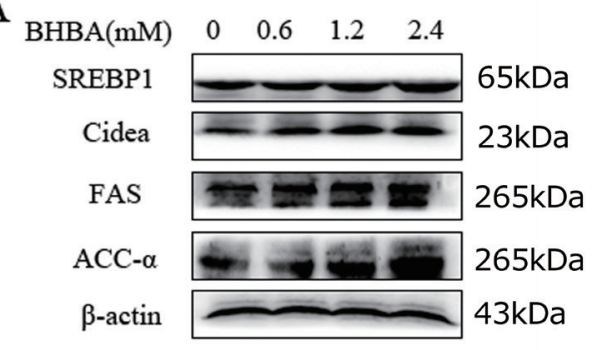

$B$
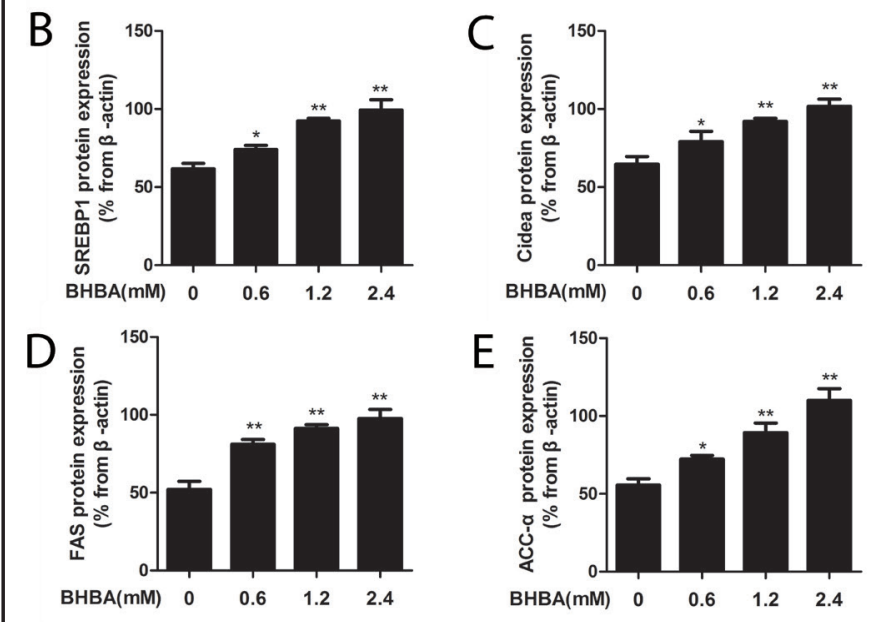

SREBP1 mediates BHBA-promoted fatty acids synthesis

SREBP1 plays an important role in the lipid synthesis. To further investigate the role of SREBP1, the cells were transfected with SREBP1 silencing adenovirus and treated with BHBA, 


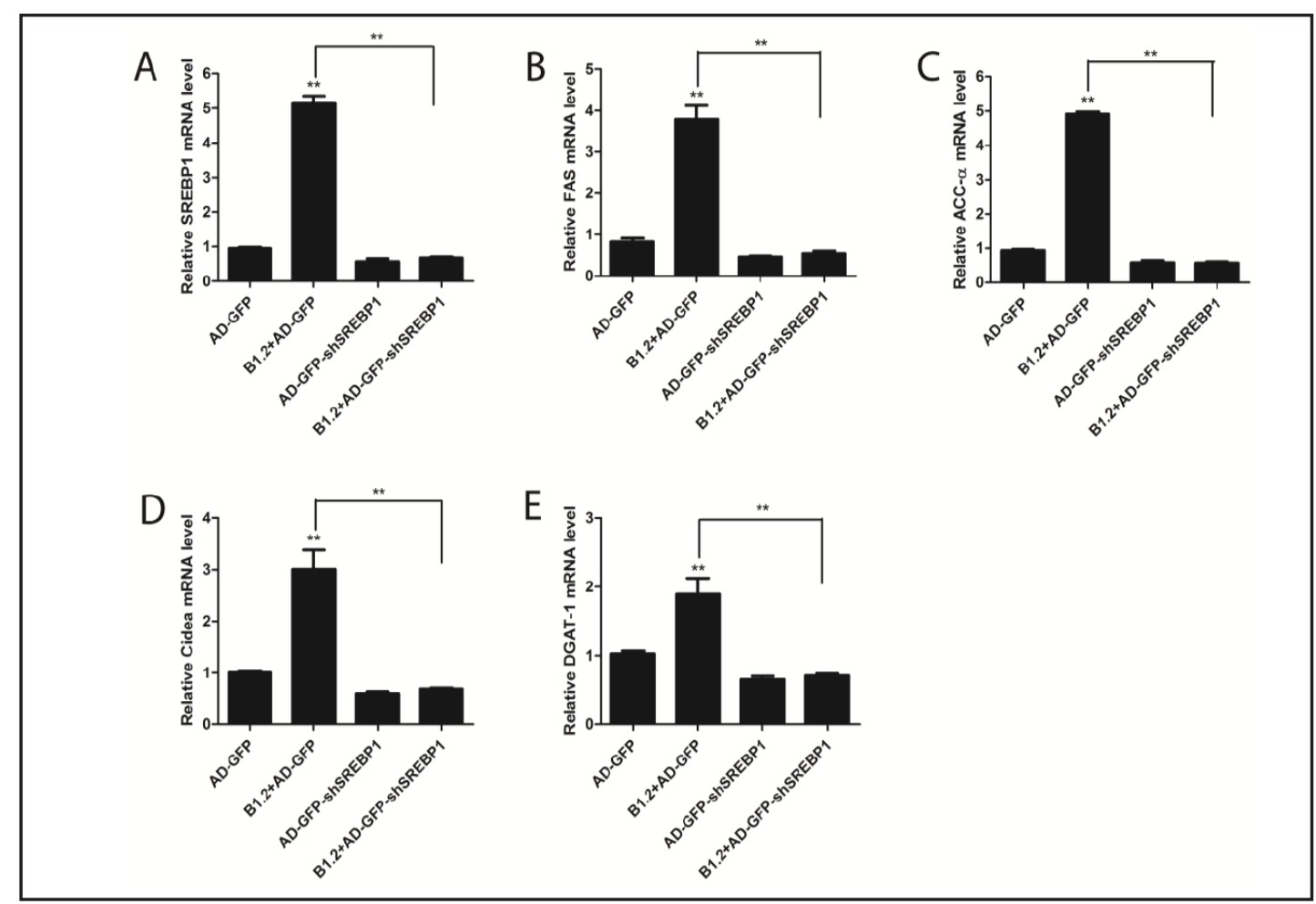

Fig. 3. BHBA activates SREBP1 to promote fatty acids synthesis in bovine mammary epithelial cells. Cells were infected with an adenovirus that silent SREBP1(AD-GFP-shSREBP1), after $24 \mathrm{~h}$, cells were treated with $1.2 \mathrm{mM}$ BHBA for another $24 \mathrm{~h}$. Control group was infected with empty adenovirus vector (AD-GFP). Nine replicate samples were used for each condition. (A) The mRNA level of SREBP1. (B) The mRNA level of FAS. (C) The mRNA level of ACC- $\alpha$. (D) The mRNA level of Cidea. (E) The mRNA level of DGAT-1. The data are shown as the mean \pm SEM. *, statistical significance $(P<0.05)$. **, statistical significance $(P<0.01)$. The symbol * and ** indicate statistical differences with the control group (AD-GFP) and the two groups which marked with horiziontal line are statistical differences.

respectively. SREBP1 silencing adenovirus significantly decreased the expression of mRNA and protein of SREBP1. Importantly, SREBP1 silencing did not affect SREBP2 expression. SREBP1 silencing significantly decreased the mRNA levels of FAS, ACC- $\alpha$, Cidea and DGAT1 in the $1.2 \mathrm{mM}$ BHBA+SREBP1 silencing group compared with the $1.2 \mathrm{mM}$ BHBA group (Fig. 3A-E). In addition, the protein levels of FAS, ACC- $\alpha$ and Cidea were also significantly decreased in the $1.2 \mathrm{mM}$ BHBA+SREBP1 silencing group (Fig. 4A-E). These results further indicate that BHBA can stimulate SREBP1 and its target molecules expression.

To evaluate the transcriptional activity of SREBP1 in bovine mammary epithelial cells after BHBA treatment, immunocytofluorescence was performed. The results showed that BHBA increased SREBP1 translocation to the nucleus, and the fluorescence intensity in the nucleus was significantly higher in the $1.2 \mathrm{mM}$ BHBA group than in the control group (Fig. $5 a-f)$. However, it was significantly decreased in the $1.2 \mathrm{mM}$ BHBA+SREBP1 silencing group (Fig. 5j-m). Overall, these results demonstrate that BHBA can increase the SREBP1 activity in bovine mammary epithelial cells.

Effects of BHBA on TG synthesis in bovine mammary epithelial cells

In order to confirm BHBA can influence the synthesis of TG, the TG content in the supernatant was measured after BHBA and SREBP1 silencing treatments. The content of TG in the supernatant was significantly higher in the $1.2 \mathrm{mM}$ and $2.4 \mathrm{mM}$ BHBA group than in the control group. However, when SREBP1 was silent, the content of TG was dramatically decreased in the $1.2 \mathrm{mM}$ BHBA+SREBP1 silencing group compared with the $1.2 \mathrm{mM}$ BHBA 
Fig. 4. SREBP1 mediates BHBA-promoted fatty acids synthesis in bovine mammary epithelial cells. Cells were treated as described in Fig. 3. (A) Western blots of $\beta$-actin, SREBP1, FAS, ACC- $\alpha$ and Cidea. (B) Relative protein expression level of SREBP1 normalized to $\beta$-actin. (C) Relative protein expression level of Cidea normalized to $\beta$-actin. (D) Relative protein expression level of FAS normalized to $\beta$-actin. (E) Relative protein expression level of ACC- $\alpha$ normalized to $\beta$-actin. The data are shown as the mean \pm SEM. $*$, statistical significance $(P<0.05)$. **, statistical significance $(P$ $<0.01)$. The symbol * and ** indicate statistical differences with the control group (AD-GFP) and the two groups which marked with horiziontal line are statistical differences.

Fig. 5. Immunofluorescence staining of SREBP1 in bovine mammary epithelial cells. Cells were treated as described in Fig. 3. Immunofluorescence staining of SREBP1 (a, d, g and $\mathrm{j}$ ) in bovine mammary epithelial cells. Images (c, f, i and $\mathrm{m}$ ) were merged with Hoechst 33258 staining images $(b, e, h$ and $\mathrm{k}$ ).
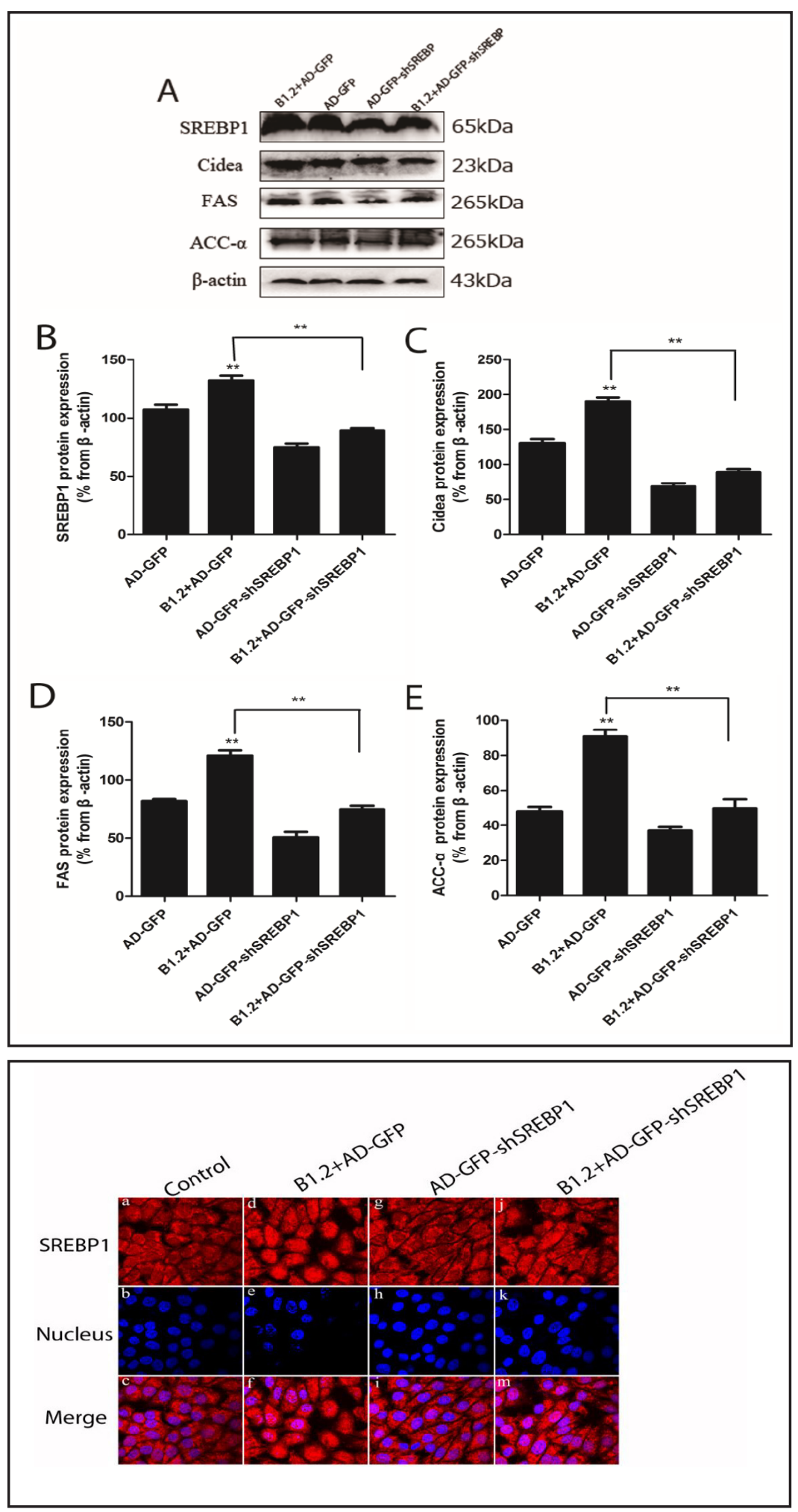

group (Fig. 6). Taken together, these results indicate that BHBA can induce SREBP1 activation and then upregulate the expression of lipid synthesis enzymes FAS, ACC- $\alpha$, Cidea and DGAT1 , thereby increasing TG secretion in bovine mammary epithelial cells. 
Fig. 6. Effects of BHBA on TG secretion in bovine mammary epithelial cells. Bovine mammary epithelial cells were treated with 0, 0.6, 1.2, 2.4 mM BHBA for $24 \mathrm{~h}$; an adenovirus that silent SREBP1 (AD-GFPshSREBP1) were delivered to the cells; after $24 \mathrm{~h}$, cells were treated with $1.2 \mathrm{mM}$ BHBA for another 24 h. Nine replicate samples were used for each condition. The data are shown as the mean \pm SEM. *, statistical significance $(P<0.05) .{ }^{* *}$, statistical significance $(P<0.01)$. The symbol * and ${ }^{* *}$ indicate statistical differences with the control group (no BHBA) and the two groups which marked with horiziontal line are statistical differences.

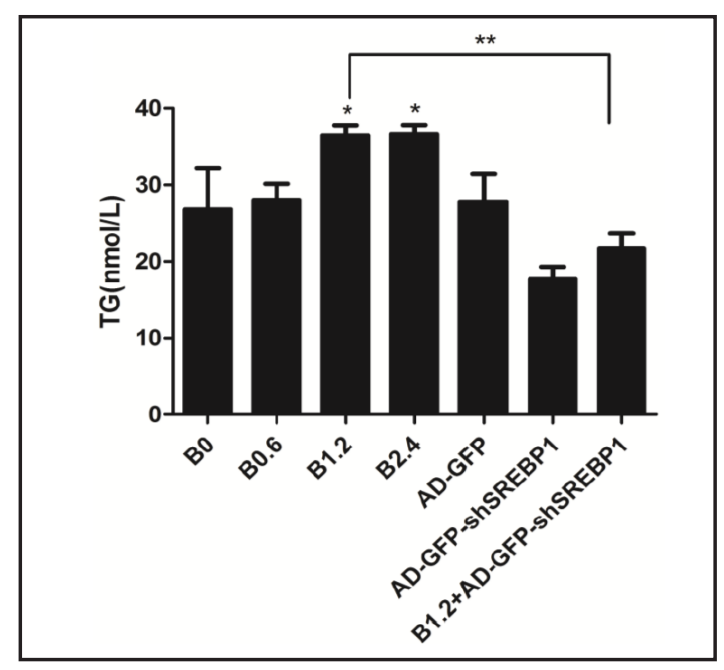

\section{Discussion}

Milk fat, consisted primarily of triglycerides (over 95\%), is the indispensable nutrients in bovine milk. The milk fatty acids involve two equal aspects, de novo synthesis in mammary epithelial cells and uptake from diet [10, 26, 27]. In ruminants, BHBA is the main milk fat precursors and supplies approximately one half of de novo synthesized fatty acids [10]. Under normal physiological conditions, butyric acid is absorbed through the rumen epithelium and metabolized into BHBA in ruminants [26]. However, excessive NEB-induced lipid mobilization leads to hyperketonemia, which displayed high blood concentrations of BHBA. Previous reports indicated that high serum BHBA had strong connection with milk production, poor reproduction and inflammation in dairy cows $[8,22]$. Thus, high concentrations of BHBA could influence milk fat synthesis in bovine mammary epithelial cells. In this study, we found that TG content was increased gradually in a BHBA-does dependent manner, and was significantly higher in the 1.2 and $2.4 \mathrm{mM}$ BHBA treatment group than in the control group. These results indicate that high concentrations of BHBA can increase the TG synthesis in mammary epithelial cells, which can explain why the milk fat could increase in dairy cows with ketosis.

We further investigated the underlying mechanism of BHBA increased the TG synthesis in mammary epithelial cells. SREBP1, a membrane-bound transcription factor, mainly regulates lipids synthesis by stimulating expression of genes involved in fatty acid and triglyceride synthesis $[14,28]$. One recent studies show that mature form SREBP1 is necessary for development of carbohydrate-induced hyper-triglyceridemia and diabetic hepatic steatosis [29]. Li et al. reported that stearic acid upregulated SREBP1, promoting triglyceride secretion and lipid droplet formation in DCMECs [12]. Cidea, located around lipid drops, regulates lipolysis and plays a key role in triglyceride synthesis and deposition [19]. Zhou et al. observed that Cidea expression was specifically increased in hepatocytes in response to saturated fatty acids intake; this upregulation was likely mediated by SREBP-1c [20]. Furthermore, Cidea acts as a transcriptional coactivator in regulating lipid secretion in mouse mammary gland [21]. In this study, we found that BHBA treatment could significantly increase the expression of SREBP1 and Cidea. Importantly, BHBA increased SREBP1 translocation to the nucleus. FAS and ACC- $\alpha$ are the target molecules of SREBP1 and are key enzymes in de novo fatty acids synthesis [12]. Furthermore, the mRNA and protein expression levels of FAS and ACC- $\alpha$ were also significantly increased in BHBA treatment groups. In addition, DGAT-1, related to TG synthesis, were also significantly upregulated. Consequently, TG content was also significantly increased after BHBA treatment. Taken together, BHBA could induce the overactivation of SREBP1 to upregulate the expression of lipid synthesis enzymes, thereby increasing TG synthesis in bovine mammary epithelial cells. 


\section{Cellular Physiology Cell Physiol Biochem 2015;37:2115-2124

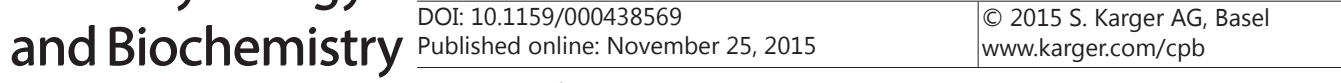 \\ Zhang et al.: $\beta$-Hydroxybutyrate Facilitates Fatty Acids Synthesis Mediated by SREBP1}

To further investigate the role of SREBP1 in the TG synthesis induced by BHBA, cultured bovine mammary cells were transfected with a SREBP silencing adenovirus and then treated with BHBA. The results showed that SREBP1 silencing significantly decreased the overexpression of Cidea, FAS, ACC- $\alpha$, and DGAT-1 induced by BHBA. The TG content also significantly decreased. These results further confirmed our conclusion. Nevertheless, Jacobs et al. demonstrated that $5 \mathrm{mM}$ BHBA had no effect on the mRNA levels of SREBP1 in bovine mammary cell line (MAC-T) [30], which is different from that of our data. The variations might be due to significant differences in BHBA treatment concentrations or cell line. Shi et al. reported that high levels of BHBA could induce oxidative stress in hepatocytes of cows [8]. Under physiological condition, BHBA is the main fat milk precursor and used for the milk fat synthesis. Our data demonstrated that BHBA could induce the activation of SREBP1 and further increase TG synthesis in mammary epithelial cells of dairy cows in vitro. These findings could explain dairy cow with NEB displayed an increase in milk fat percentage. However, excessive NEB-induced high blood concentrations of BHBA might affect other physiological mechanisms and could influence milk fat synthesis in mammary epithelial cells.

\section{Conclusions}

In summary, our results suggest that BHBA can induce the activation of SREBP1/Cidea pathway and then upregulate the expression of FAS, ACC- $\alpha$ and DGAT-1, thereby increasing TG synthesis in mammary epithelial cells.

\section{Acknowledgements}

This work was supported by the Program for the National Key Technology R\&D Program (grant no. 2012BAD12B03), the National Natural Science Foundation of China (Beijing, China; grant no. 31402265, 31472247, 31460681), and the scientific frontier and interdisciplinary innovation project of Jilin University (450060501485).

\section{Disclosure Statement}

None to declare.

\section{References}

1 Li X, Chen H, Guan Y, Lei L, Liu J, Yin L, Liu G, Wang Z: Acetic acid activates the AMP-activated protein kinase signaling pathway to regulate lipid metabolism in bovine hepatocytes. PLoS One 2013;8:e67880.

2 Smith G, McCarthy S, Rook J: Synthesis of milk fat from $\beta$-hydroxybutyrate and acetate in lactating goats. J Dairy Res 1974;41:175-191.

3 Li P, Liu Y, Zhang Y, Long M, Guo Y, Wang Z, Li X, Zhang C, He J, Liu G: Effect of Non-Esterified Fatty Acids on Fatty Acid Metabolism-Related Genes in Calf Hepatocytes Cultured in Vitro. Cell Physiol Biochem 2013;32:1509-1516.

4 Adewuyi AA: Non esterified fatty acids (NEFA) in dairy cattle. A review. Vet Quart 2005;27:117-126.

5 Oetzel GR: Monitoring and testing dairy herds for metabolic disease. Vet Clin North Am Food Anim Pract 2004;20:651-674.

6 Rollin E, Berghaus R, Rapnicki P, Godden S, Overton M: The effect of injectable butaphosphan and cyanocobalamin on postpartum serum $\beta$-hydroxybutyrate, calcium, and phosphorus concentrations in dairy cattle. J Dairy Sci 2010;93:978-987. 


\section{Cellular Physiology Cell Physiol Biochem 2015;37:2115-2124 \begin{tabular}{l|l} 
and Biochemistry & $\begin{array}{l}\text { DOI: 10.1159/000438569 } \\
\text { Published online: November 25, } 2015\end{array}$ \\
\hline
\end{tabular}

7 Suthar V, Canelas-Raposo J, Deniz A, Heuwieser W: Prevalence of subclinical ketosis and relationships with postpartum diseases in European dairy cows. J Dairy Sci 2013;96:2925-2938.

8 Shi X, Li X, Li D, Li Y, Song Y, Deng Q, Wang J, Zhang Y, Ding H, Yin L: $\beta$-Hydroxybutyrate Activates the NF- $\kappa B$ Signaling Pathway to Promote the Expression of Pro-Inflammatory Factors in Calf Hepatocytes. Cell Physiol Biochem 2014;33:920-932.

9 Laeger T, Metges CC, Kuhla B: Role of $\beta$-hydroxybutyric acid in the central regulation of energy balance. Appetite 2010;54:450-455.

10 Bauman DE, Griinari JM: Nutritional regulation of milk fat synthesis. Annu Rev Nutr 2003;23:203-227.

11 Duffield T, Lissemore K, McBride B, Leslie K: Impact of hyperketonemia in early lactation dairy cows on health and production. J Dairy Sci 2009;92:571-580.

12 Li N, Zhao F, Wei C, Liang M, Zhang N, Wang C, Li Q-Z, Gao X-J: Function of SREBP1 in the Milk Fat Synthesis of Dairy Cow Mammary Epithelial Cells. Int J Mol Sci 2014;15:16998-17013.

13 Wang X, Sato R, Brown MS, Hua X, Goldstein JL: SREBP-1, a membrane-bound transcription factor released by sterol-regulated proteolysis. Cell 1994;77:53-62.

14 Eberlé D, Hegarty B, Bossard P, Ferré P, Foufelle F: SREBP transcription factors: master regulators of lipid homeostasis. Biochimie 2004;86:839-848.

15 Shimano H, Yahagi N, Amemiya-Kudo M, Hasty AH, Osuga J-i, Tamura Y, Shionoiri F, Iizuka Y, Ohashi K, Harada K: Sterol regulatory element-binding protein-1 as a key transcription factor for nutritional induction of lipogenic enzyme genes. J Biol Chem 1999;274:35832-35839.

16 McFadden J, Corl B: Activation of liver X receptor (LXR) enhances de novo fatty acid synthesis in bovine mammary epithelial cells. J Dairy Sci 2010;93:4651-4658.

17 Xu L, Zhou L, Li P: CIDE proteins and lipid metabolism. Arterioscl Throm Vas 2012;32:1094-1098.

18 Wang R, Kong X, Cui A, Liu X, Xiang R, Yang Y, Guan Y, Fang F, Chang Y: Sterol-regulatory-element-binding protein $1 \mathrm{c}$ mediates the effect of insulin on the expression of Cidea in mouse hepatocytes. Biochem $\mathrm{J}$ 2010;430:245-254.

19 Puri V, Ranjit S, Konda S, Nicoloro SM, Straubhaar J, Chawla A, Chouinard M, Lin C, Burkart A, Corvera S, Perugini RA, Czech MP: Cidea is associated with lipid droplets and insulin sensitivity in humans. Proc Natl Acad Sci U S A 2008;105:7833-7838.

20 Zhou L, Xu L, Ye J, Li D, Wang W, Li X, Wu L, Wang H, Guan F, Li P: Cidea promotes hepatic steatosis by sensing dietary fatty acids. Hepatology 2012;56:95-107.

21 Wang W, Lv N, Zhang S, Shui G, Qian H, Zhang J, Chen Y, Ye J, Xie Y, Shen Y: Cidea is an essential transcriptional coactivator regulating mammary gland secretion of milk lipids. Nat Med 2012;18:235-243.

22 Ospina P, Nydam D, Stokol T, Overton T: Associations of elevated nonesterified fatty acids and $\beta$-hydroxybutyrate concentrations with early lactation reproductive performance and milk production in transition dairy cattle in the northeastern United States. J Dairy Sci 2010;93:1596-1603.

23 Iwersen M, Klein-Jöbstl D, Pichler M, Roland L, Fidlschuster B, Schwendenwein I, Drillich M: Comparison of 2 electronic cowside tests to detect subclinical ketosis in dairy cows and the influence of the temperature and type of blood sample on the test results. J Dairy Sci 2013;96:7719-7730.

24 van der Meide W, Guerra J, Schoone G, Farenhorst M, Coelho L, Faber W, Peekel I, Schallig H: Comparison between quantitative nucleic acid sequence-based amplification, real-time reverse transcriptase PCR, and real-time PCR for quantification of Leishmania parasites. J Clin Microbiol 2008;46:73-78.

25 Livak KJ, Schmittgen TD: Analysis of relative gene expression data using real-time quantitative PCR and the 2- $\Delta \Delta \mathrm{CT}$ method. Methods 2001;25:402-408.

26 Månsson HL: Fatty acids in bovine milk fat. Food Nutr Res 2008;52.

27 Dils R: Comparative aspects of milk fat synthesis. J Dairy Sci 1986;69:904-910.

28 Brown MS, Goldstein JL: The SREBP pathway: regulation of cholesterol metabolism by proteolysis of a membrane-bound transcription factor. Cell 1997;89:331-340.

29 Moon Y-A, Liang G, Xie X, Frank-Kamenetsky M, Fitzgerald K, Koteliansky V, Brown MS, Goldstein JL, Horton JD: The Scap/SREBP pathway is essential for developing diabetic fatty liver and carbohydrate-induced hypertriglyceridemia in animals. Cell Metab 2012;15:240-246.

30 Jacobs A, Dijkstra J, Liesman J, VandeHaar M, Lock A, van Vuuren A, Hendriks W, van Baal J: Effects of short-and long-chain fatty acids on the expression of stearoyl-CoA desaturase and other lipogenic genes in bovine mammary epithelial cells. Animal 2013;7:1508-1516. 